\title{
СОЦИАЛИЗАЦИЯ ЛИЧНОСТИ В СОВРЕМЕННОМ МЕДИЙНОМ ОБЩЕСТВЕ
}

\author{
В. Н. ВАРИЧ
}

\section{Брестский государственный технический университет, г. Брест, Беларусь}

Для современного информационного общества характерны фундаментальные изменения в понимании природной и социальной реальности, сущности происходящих в обществе процессов и особенностей личностного становления. Отказ от классического и модернистского дискурса, от традиционных форм познания и оценивания сопровождается серьезными изменениями в способах и механизмах трансляции социального опыта, которые обнаруживают себя в первую очередь в разрыве преемственности ценностей и норм культуры. Ценностно-смысловое содержание мировоззрения приобретает черты бессистемности и неопределенности, тогда как любой субъект социальной жизни нуждается в постоянном соотнесении своих мыслей и поступков с той ценностной иерархией, которая преобладает в современном ему обществе. В том случае, если таковая иерархия отчетливо не выражена и не воспринимается большинством как ценностный ориентир, личностная культурная идентификация оказывается весьма затрудненной.

Духовный поиск и стремление к самоопределению свойственны всем молодым людям, однако в настоящее время этот поиск и стимулируется, и осложняется ситуацией мировоззренческого плюрализма и несовпадающими установками официальных и неофициальных средств массовой коммуникации. Отсутствие ясно формулируемой и признанной обществом единой системы ценностей приводит к тому, что каждый юный человек вынужден самоопределяться в буквальном смысле слова. На основе внутреннего ценностного чувства (которое, по мнению Э. Гартмана, есть у всех людей и различается только «высотой») или даже по принципу «нравится - не нравится» молодые люди производят селекцию тех идей, ценностей и значений, которые транслируют семья, школа, трудовые коллективы, сообщества в социальных сетях или обычные новостные источники. Такой путь, безусловно, представляется более тернистым, нежели социализация в традиционном обществе с господствующей системой ценностей, однако подобная социализация имеет и несомненные достоинства, поскольку только так и может сформироваться гражданское общество - путем исканий, проб и ошибок, которые совершает каждая личность.

Экспоненциальное развитие информационных технологий и связанные с ним социокультурные изменения находят выражение в постоянно возрастающем многообразии форм экономической, социальной, политической и духовной жизни. Многомерность социальной реальности и интенсификация межкультурной коммуникации ставят перед субъектом проблему выбора в бесконечном информационном потоке тех знаний, значений, норм и смыслов, которые в наибольшей степени соответствуют его ценностным ориентациям. Именно поэтому в современном информационном обществе способность личности к такому выбору оказывается чрезвычайно востребованной, а формируется она в процессе социализации.

Под социализацией, как правило, понимают «двусторонний процесс (1) постоянной передачи обществом и (2) освоения индивидом в течение всей его жизни социальных норм, культурных ценностей и образцов поведения, позволяющий индивиду функционировать в данном обществе» [1, с. 139]. Социализация представляет собой не только двусторонний, но и многоступенчатый процесс, в котором выделяют два основных взаимосвязанных этапа. В ходе первичной социализации, которая осуществляется, как правило, в семье, индивид усваивает язык, нормы поведения и базовые знания об окружающем мире. На этом этапе индивид не осуществляет ни выбора, ни оценок - вхождение в ту культуру, в которой воспитывается ребенок, для него является естественным процессом. Второй этап начинается с осознания усвоенных норм, ценностей и значений, после которого возможны их оценка и обсуждение, а также внесение корректировок, обусловленных собственным мнением. Собственно, второй этап социализации продолжается на протяжении всей осознанной жизни 
человека и, в свою очередь, включает в себя процессы десоциализации (отказа от прежнего социального опыта) и ресоциализации (усвоения новых норм и ценностей). В дополнение можно заметить, что ресоциализация в условиях постоянного ускорения темпов общественного развития оказывается необходимой значительно чаще, чем это бывало в традиционном и индустриальном обществе.

Как бы то ни было, система ценностных ориентаций личности и определяемые ею критерии для оценивания всего происходящего вокруг личности и в ее духовном мире формируются в ходе социализации. В сложившейся системе - независимо от того, является ли она косной или динамичной, - можно выделить три подсистемы: когнитивная подсистема содержит знания и суждения о предмете оценивания, эмотивная подсистема включает эмоциональные оценки, поведенческая подсистема определяет социальные действия личности. Принятие или отрицание каких-либо ценностей, их усиление или снижение, удержание или отказ от них осуществляются в соответствии со смысловыми представлениями личности. Со своей стороны, ценностные ориентации являются основой экзистенциальных характеристик личности. Иными словами, ценности личности одновременно выступают и как источники, и как носители смыслов, значимых для человека.

Воспринятые и усвоенные в ходе социализации ценности образуют в сознании личности ценностную иерархию, в которой есть как безусловные, так и менее значимые ценности. Критерии такого ранжирования определяются, во-первых, теми позициями, которые ценности занимают в ценностной системе общества, а во-вторых, субъективными установками личности. Поэтому ценностная система личности является многоуровневой, многомерной и нелинейной, выступая в качестве посредника между личными и коллективными ценностями. Таким образом, формирование личностных ценностных ориентаций осуществляется на основе индивидуального опыта, который включен в социальный опыт. Поэтому они имеют и двойное функциональное назначение - закрепляют в сознании и поведении те культурные нормы и установки, которые способствуют успешной социализации, и в то же время являются критериями для оценки мотивов и стимулов собственного поведения.

Успешная социализация выражается не только (и не столько) в обретении желаемого социального статуса, сколько в способности личности дифференцировать ценности по степени их значимости. Для этого необходимо научиться определять, являются ли ценностями какиелибо конкретные значимые объекты, либо же ценность является тем свойством (характеристикой), которое можно отнести к разнообразным объектам. Если рассматривать ценность как отношение к различным объектам, то возникает еще один вопрос: определяется ли ценностное отношение сознанием самого субъекта или же оно формируется социальной общностью. В первом случае принятие ценностей происходит на основе личного выбора, во втором - в результате интериоризации уже имеющихся ценностных образцов и стереотипов. Сформированная ценностная система личности имеет объективную и субъективную стороны. К объективной стороне относятся те ценности, которые генерируются и транслируются обществом в качестве необходимого условия социального взаимодействия: «... шкала ценностей оказывается таким образом свободной от субъективных и изменчивых оценок индивидов. Последние находят вне себя уже устоявшуюся классификацию, к которой вынуждены приспосабливаться» [2, с. 106]. К субъективной стороне - те оценки и установки самой личности, которые формируют ее когнитивно-эмоциональные и поведенческие характеристики. Согласование обеих сторон осуществляется в процессе ценностной адаптации, которая является необходимым элементом и собственно социализации, и ресоциализации. Адаптация может производиться в двух противоположных направлениях, одним из которых является стремление изменить внешние условия в соответствии со своими ценностями, а другим - «подгонка» личностных оценок под культурные образцы и стереотипы определенного общества. Интеллектуальное, оценочное и поведенческое отношение к миру, определяемое ценностными ориентациями личности, иначе можно назвать ее идентичностью, формирование которой «происходит на протяжении всей человеческой жизни в постоянном ситуативном противоречии с реальным окружением» [3, с. 123].

Если вернуться к трем подсистемам ценностных ориентаций личности и проанализировать их формирование применительно к современному обществу, то 
обнаруживаются обстоятельства, затрудняющие социализацию и успешную ценностную адаптацию личности.

1. Когнитивная составляющая формируется в системе общеобразовательной средней школы и, в случае продолжения обучения, в системе высшего образования. При этом можно констатировать, что по окончании средней школы многие ее выпускники не имеют сформированной научной картины мира и, соответственно, критериев, по которым можно оценивать знания на предмет их истинности и аутентичности. Виной ли то тому недостатки организации учебного процесса, неудачные учебники или отсутствие интереса к ним из-за возможности мгновенно получить любую информацию, фактические обстоятельства именно таковы.

2. Эмотивная подсистема складывается в процессе первичной социализации, во время которой многие родители, к сожалению, не уделяют достаточного внимания общению с ребенком по смысложизненным вопросам, а в процессе воспитания не стремятся «выработать совокупность тех принципов, которые обеспечивают на основе самообразования и самовоспитания успешную адаптацию личности к жизни в постоянно меняющемся мире» [4, с. 179].

3. Поведенческая подсистема формируется во взаимосвязи с когнитивной и эмотивной, включая базовые и инструментальные ценности личности, ее убеждения и мотивы деятельности. Как отмечалось в начале статьи, современное медийное общество характеризуется плюрализмом всех форм социальной жизни, и каждое направление мысли, художественное течение, политическая идея рассматриваются как равноправные, одинаково значимые и одинаково ценные. Объективная сторона системы ценностных ориентаций личности складывается поэтому в тех условиях, когда индивид постоянно попадает в разнородные ситуации с различными социокультурными кодами, не принимает ни одну из них как единственно истинную и перемещается между ними только из соображений привлекательности [см. 3, с. 123].

Подводя итоги сказанному, можно отметить, что в современном обществе на смену устойчивым ценностным системам общества и развитым системам ценностных ориентаций личности приходит новая организация ценностей в индивидуальном и коллективном сознании. Для нее характерны эклектический характер, нерефлексивность, некритичность, быстрые изменения (вплоть до инверсий), фрагментарность. Как справедливо замечает О. А. Митрошенков, в таком миропредставлении перемены оказываются лучше, чем стабильность, предчувствия - лучше настоящего, отношения превращаются в транзакции, а инфантилизм преобладает над зрелостью [5, с. 188].

\section{Литература}

1. Ковалева, И. А. Социализация / И. А. Ковалева // Знание. Понимание. Умение. - 2004. - № 1.

2. Дюркгейм, Э. Ценностные и «реальные» суждения / Э. Дюркгейм // Социологические исследования. - 1991. - № 2.

3. Урмина, И. А. Многомерная идентичность человека в современной организации / И. А. Урмина // Вопросы социальной теории. - 2012. - Т. 2.

4. Варич, В. Н. Трансформация современной семьи и семейная политика / В. Н. Варич, И. А. Шебанова // Диалог культур в эпоху глобальных рисков : материалы Международной научной конференции «Инновационные стратегии в современной социальной философии», Минск, 17-18 мая 2016 г. - Ч. 1. - Минск : РИВШ, 2016. - 236 с.

5. Митрошенков, О. А. Пространство и феноменология духовной ситуации человека в современном мире / О. А. Митрошенков // Вопросы социальной теории. - 2012. - Т. 2.

Статья раскрывает механизмы формирования системы ценностей личности в процессе социализации и особенности этого процесса в современном обществе.

The article reveals the mechanisms of the formation of the personal value system in the process of socialization and the features of this process in modern society. 